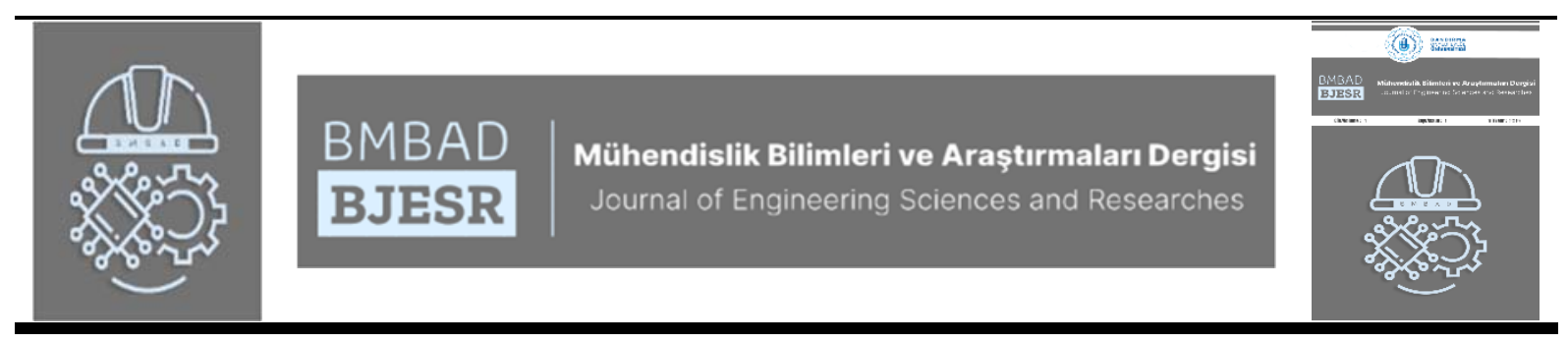

\title{
Sonlu Elemanlar Yöntemi ile Dağttım Transformatörlerinin Harmonik Yük Kayıplarının Analizi
}

\author{
Analysis of Harmonic Load Losses of Distribution Transformers Using Finite \\ Element Method
}

\section{YıIdırım ÖZÜPAK $(\mathbb{D}$}

Dicle Üniversitesi, Silvan MYO, Elektrik ve Enerji bölümü, Diyarbakır, Türkiye

yildirimozupak@gmail.com

Araştırma Makalesi/Research Article

\begin{tabular}{l}
\hline A R T I C L E I N F O \\
Article history \\
Received :30 December 2020 \\
Accepted : 17 January 2021
\end{tabular}

Keywords:

Transformer, Harmonic Load, Maxwell, Magnetic Flux, Losses \begin{abstract}
A B S T R A C T
Estimating losses in transformers is important for both manufacturers and users. With the development of technology, harmonics in power systems are increasing. Transformers, which are an important component of the power system, also carry harmonic load currents. It is important to be able to accurately calculate the load losses in order to predict the hot spot temperatures and total losses during operation. Different methods have been developed in this regard. Among these methods, Finite Element Method is well known and its accuracy has been proven in engineering studies. Transformer designers have specific programs developed and used for design and analysis. In this study, ANSYS@Maxwell software and simulation program is used to design a parametric model of a power transformer. In this way, the load losses of the transformer in both normal operating conditions and harmonic operating conditions were obtained. In addition, the effect of harmonic loads on magnetic flux distribution has been investigated.
\end{abstract}

(C) 2020 Bandirma Onyedi Eylul University, Faculty of Engineering and Natural Science. Published by Dergi Park. All rights reserved.

\section{Ö Z E T}

Transformatörlerde meydana gelen kayıpları tahmin etmek, hem üreticiler hem de kullanıcılar için önemlidir. Teknolojinin gelişmesiyle birlikte güç sistemlerinde harmonikler artmaktadır. Güç sisteminin önemli bir bileşeni olan transformatörler de harmonikli yük akımları taşımaktadır. Çalışma sırasında sıcak nokta sıcaklıklarını ve toplam kayıpları tahmin edebilmek için yük kayıplarını doğru bir şekilde hesaplayabilmek önemlidir. Bu konuda farklı yöntemler geliştirilmiştir. Bu yöntemlerden Sonlu Elemanlar Yöntemi iyi bilinmekte ve doğruluğu mühendislik çalışmalarında kanıtlanmıştır. Transformatör tasarımcıları, tasarım ve analiz için geliştirilen ve kullanılan özel programlara sahiptirler. Bu çalışmada, ANSYS@Maxwell yazılım ve simülasyon programı bir güç transformatörünün parametrik bir modelini tasarlamak için kullanılmıştır. Bu sayede transformatörün hem normal çalışma koşullarındaki hem de harmonikli çalışma koşullarındaki yük kayıpları elde edilmiştir. Ayrıca harmonikli yüklerin manyetik akı dağılımına etkisi incelenmiştir.

\section{Anahtar Kelimeler:}

Transformatör, Harmonik Yük, Maxwell, Manyetik Ak1, Kayılar
(C) 2020 Bandırma Onyedi Eylül Üniversitesi, Mühendislik ve Dağa Bilimleri Fakültesi. Dergi Park tarafından yayınlanmaktadır. Tüm Hakları Saklıdır. 


\section{GIRIŞ}

Güç transformatörleri, elektrik iletim ve dağıtım sisteminin önemli bir parçasıdır. Artan enerji fiyatları, güç transformatörlerinde kayıplara vurgu yapmayı gerekli kılmıştır. Sistemde elektroniklerin kullanımının artması ile akımlardaki harmonik bozulma artmıştır. Bu bozulma, transformatörlerde kayıpları arttırmaktadır. Bu durum kontrol altında tutulmazsa, transformatörün sıcak nokta sıcaklıklarının artmasına ve yalıtımın bozulmasına neden olabilir [1].

Güç transformatörlerinde yük kayıpları üç ana bölüme ayrılabilir: DC kayıpları, sargılardaki girdap akımı kayıpları ve transformatörün tank, kelepçeler, kilit plakaları gibi diğer iletken kısımlarında meydana gelen kaçak kayıplardır. DC kayıplar, hesaplanması ve ölçülmesi en kolay olanlardır. Sargılardaki ve transformatörün diğer bölümlerindeki girdap akımı kayıplarının ölçüm sırasında ayrılması mümkün değildir. Ancak hesaplama ile tahmin edilebilir. Başıboş kayıplar, iki boyutlu yaklaşımla veya üç boyutlu sonlu eleman programlarında modelleme yoluyla tahmin edilebilir [2].

Kullanıcıların bakış açısından bakıldığında, DC kayıplar ve kaçak kayıplar, transformatörün test raporunda mevcuttur. Bu iki parametreyi bilindikten sonra yük akımının harmonik içeriği de biliniyorsa transformatörde meydana gelen toplam kayıpları hesaplamak için bir çarpma faktörü tahmin edebilir.

Bir transformatörün yükleme kapasitesinin ve faydalı ömrünün sınırlarını tahmin etmek için, transformatör sargılarının sıcak nokta sıcaklığını tahmin etmek gerekir. Sinüzoidal koşullar altında sıcak nokta sıcaklığını belirlemek için bugüne kadar birçok yöntem önerilmiştir. Isı transferi teorisinin temellerine dayanan eşdeğer bir devre şeklinde bir transformatör termal modelleme yaklaşımı önerilmiştir [3]. Yalıtımın bozulma süresini değerlendirmek için tam simülasyon ve yenileme süreci yaklaşımları sunulmuştur. Transformatörün verimli ömrü, ulaşma süresi tasarım ömrü ve belirli bir zamanda arıza olasılığı gibi bazı ilgili güvenilirlik parametrelerinin tahminleri de sunulmuştur [4]. Transformatörün farklı noktalarındaki sıcaklığı ve sıcaklık dağılımını tahmin etmek için analitik yöntemler, genelleştirilmiş 1 sı iletimi modelini kullanan kapalı form matematiksel tekniğe dayalı olarak sunulmuştur [5]. Bununla birlikte, sıcak nokta sıcaklığını harmonik koşullar altında değerlendirmenin birkaç yöntemi vardır. Sıcak nokta sıcaklığını ve transformatör ömrünü tahmin etmek için geleneksel transformatör eşdeğer devresine benzer bir model kullanılmıştır [6].

Sürekli gelişen teknoloji ile birlikte sistemlerdeki yükler her geçen gün çeşitlilik kazanmaktadır. Bu yüklerin daima lineer yükler olması istenir. Fakat yarı iletken teknolojisinin son yıllarda hızla gelişmesinin etkisi ve değişik çalışma şartları ile sistemlerdeki lineer olmayan yüklerde büyük bir artış görülmektedir.

Karakteristiği doğrusal olmayan yüklere nonlineer yükler denir. Uç karakteristiklerine baz alınarak elemanlar, nonlineer ya da lineer olarak adlandırılır. Bir dirençte gerilim-akım, bobinde akım-akı, kondansatörde gerilim-yük ilişkileri lineerliği tayin etmektedir. Sistemde harmonik akım ve gerilimlerin meydana gelmesine sistemde mevcut olan linner olamayan elemanlar sebep olurlar [7]. Transformatörler, kesintisiz güç kaynakları (UPS), dönüş̧ürücüler ve güç elektroniği elemanları sistemde harmoniklerin meydana gelmesine sebep olan yüklerdir. Harmonikler sistemde ek enerji kayıplarına, ısınmalara, yalıtımlarının zarar görmelerine yol açarlar. Bu nedenle, mümkün olmasa bile bir sistemde harmoniklerin olmaması sistem açısından önemlidir. Harmoniklerin elimine etmenin için en önemli metodu harmonik filtreler kullanmaktır. Güç transformatörleri genel olarak gerilim ve akımın sinüzoidal olduğu şartlarda kullanılmak üzere tasarlanırlar [8]. Ancak, doğrusal olmayan yükler, gelişen teknoloji ile birlikte modern güç sistemlerinde giderek artmaktadır. Bu nedenle, hat gerilimleri ve akımları genellikle harmonik olarak bozuk veya sinüzoidal olmayan dalga şekillerine sahiptirler. Transformatörler, AC güç şebekelerinde elektrik enerjisinin iletim ve dağıtımının en önemli ekipmanlardan biridir. Elektrik mühendisliği literatüründe, nüve ve sargı kayıplarının ölçümü ve hesaplanması sinüzoidal gerilim ve doğrusal yük (sinüzoidal akım) koşulları için iyi bilinmektedir. Bir transformatörün yüksüz kaybı, bir yük sağlamadığı zaman çekirdeği ve enerjili sargısı tarafindan tüketilen aktif güçlerin toplamıdır [9-11]. Yüksüz kayıp, yüksüz durumda nominal frekansta sinüzoidal uyarma gerilimi altında sargı kaybının oldukça küçük olması nedeniyle pratik olarak çekirdek kayıp olarak kabul edilir. Ek olarak, bir güç transformatörünün sargı kaybı, nominal yükleme durumu için temel kaybından önemli ölçüde daha büyük olduğundan, sargı kaybı genellikle yük kaybı olarak adlandırılır.

Harmonik koşullar altında transformatörün sıcak nokta sıcaklığını ve yükleme kabiliyetini tahmin etmek için termal modellerin olmaması, transformatör performansını analiz etmek için güvenilir dinamik modeller geliştirmeyi amaçlayan mevcut çalışmayı yapmaya teşvik etmiştir.

$\mathrm{Bu}$ çalışmada, geometrileri bilindiğinde transformatör sargılarındaki yük kayıplarını hesaplamanın bir yöntemi açıklanmıştır. Bu kayıplar, DC kayıpları ve girdap akımı kayıpları olarak ayrılabilirler. DC kayıplarının hesaplanması kolaydır. Girdap akımı kayıpları ise frekansa ve geometriye bağlıdır. Bu kayıpları makul bir doğrulukla tahmin etmek için basitleştirilmiş formüller olsa da, modern Sonlu Eleman Yöntemi daha iyi bir sonuç vermektedir [13-15]. Genellikle basitleştirilmiş formüller ile akı yoğunluğunun radyal bileşeni ihmal edilmektedir. Gerçekte ise bu bileşen, sargı uçlarında baskın hale gelir ve ihmal edilemez [16,17]. Piyasada girdap akımı kayıpları sorununu çözmek için kullanılabilecek birkaç genel amaçı Sonlu Eleman Programı bulunmaktadır. Bu çalışmada, Sonlu Elemanlar Yöntemine dayanan ANSYS@Maxwell kullanılarak modellenen trafonun analizi anlatılmaktadır. Temel frekans için yük kayıpları hesaplandıktan sonra, aşırı harmonik akımlar için kayıpları hesaplamak da daha kolay olmaktadır. Harmonik akımlarla yük kayıplarını hesaplamak için bir yöntem açıklanmıştır. 


\section{SARGILARDAKİ KAYIPLARIN HESAPLANMASI}

Sargılardaki yük kayıpları, iletkenlerin direnci ile verilen DC kayıplarına ve kaçak akının yoğunluğuna bağlı girdap akımı kayıplarına ayrılabilir [4,5].

\subsection{Sargılarda DC kayıpları}

Sargıdaki DC kaybı aşağıdaki formülden hesaplanabilir:

$P_{D C}=J^{2} M_{c u} / \sigma$

Burada J akım yoğunluğu ve $M_{c u}$ aktif bakırın toplam kütlesidir.

DC kayıpları frekanstan bağımsızdır, bu nedenle akımların aşııı harmonik içeriği akımın karesiyle orantılıdır. DC kayıplarını hesaplamak için karmaşık bir programa gerek yoktur.

\subsection{Sargılardaki Eddy Akımı Kayıpları}

Sargıdaki girdap akımı kayıpları, iletken boyutları, akı yoğunluğu ve frekans gibi faktörlere büyük ölçüde bağlıdır. Akımın harmonik içeriği çok daha düşük olmasına rağmen, girdap kayıpları frekansın karesi ile orantılı olduğundan göz ardı edilemezler.

Bu durumda, sargının her bir kısmındaki girdap kayıplarını hesaplamak için geometrinin akı yoğunluğu dağılımı bilinmelidir. Şekil l'de gösterildiği gibi küresel koordinatlarda transformatör sargısında bir iletken düşünün.

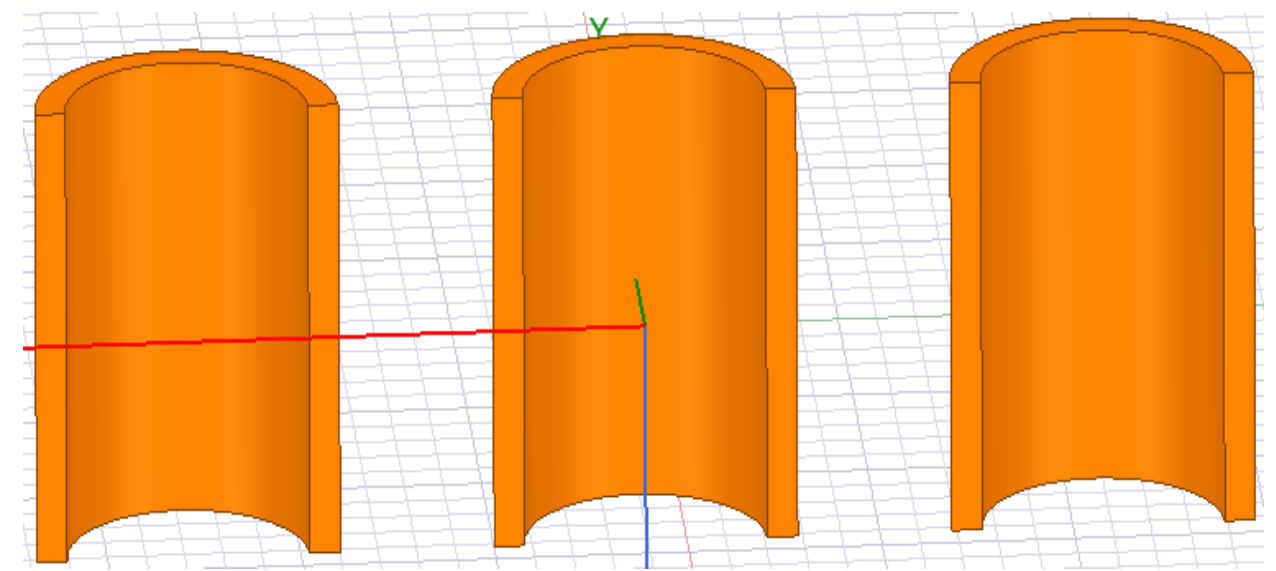

Şekil 1. Sargıda iletkenlerin küresel gösterimi.

Elektrik alanı ile akı yoğunluğu arasındaki ilişki şu şekildedir:

$\nabla \times \vec{E}=-\frac{\partial}{\partial t} \vec{B}$

Burada $E$, girdap akımlarına neden olan indüklenen elektrik alanıdır,

$B$, sızıntı alanından kaynaklanan manyetik akı yoğunluğudur. Bu akı yoğunluğu yük akımları tarafından üretilir.

Silindirik koordinatlarda:

$\nabla \times \vec{E}=\frac{\partial}{\partial z} \vec{E} \cdot \vec{a}_{r}+\left(\frac{\partial}{\partial r} E+\frac{\vec{E}}{r}\right) \cdot \vec{a}_{z}=-\frac{\partial}{\partial t} \vec{B}$

şeklindedir.

Akı yoğunluğu, eksenel ve radyal bileşenlerine ayrıştırılabilir.

$\vec{B}=B_{r} \cdot \vec{a}_{r}+B_{z} \cdot \vec{a}_{z}$

Önce denklemin radyal bileşeni düşünülürse:

$\frac{\partial}{\partial z} \vec{E}=-j \omega B_{r}$ 
$\vec{E}=-j \omega B_{r} z+\vec{E}(0)$

Akım yoğunluğu;

$j=\sigma \vec{E}=-j \omega B_{r} z+\vec{\jmath}(0)$

Simetriden dolay $1, \mathrm{j}(0)=0$.

Akı yoğunluğunun radyal bileşenine bağlı olarak sargılardaki güç kaybı şu şekilde ifade edilmektedir [7]:

$P_{\text {rad }}=\frac{1}{2} \iiint_{V} \frac{j^{2}}{\sigma} d V=\omega^{2} \sigma B_{r}^{2} 2 \pi r_{0} t \int_{0}^{r_{0}+b / 2} z^{2} \cdot d z$

$P_{\text {rad }}=\frac{\omega^{2} \sigma B_{r}^{2} 2 \pi r_{0} t b^{3}}{24}$

Burada $P_{r a d}$, akı yoğunluğunun radyal bileşeninden kaynaklanan girdap kaybıdır, $B_{\mathrm{r}}$ akı yoğunluğunun radyal bileşenidir.

Akı yoğunluğunun eksenel bileşeninden kaynaklanan kaybı hesaplamak için, kayıp denkleminin z bileşenini alırız.

$\left(\frac{\partial}{\partial r} E+\frac{\vec{E}}{r}\right) \cdot \vec{a}_{z}+j \omega \vec{B}_{z}=0$

Bu denklem, yeni bir $\mathrm{u}=\mathrm{E} / \mathrm{r}$ değiş̧keni eklenerek ve değişkenleri ayrılarak çözülebilir. Akım yoğunluğunun voltaj çarpı iletkenlik olduğunu göz önünde bulundurularak, akım yoğunluğu için genel çözüm böyle yazılabilir:

$j=\frac{k \sigma}{2 r}-j \omega B_{z} r$

Belirli çözümü bulmak için, akım yoğunluğunu kesit üzerinden birleştirilirse toplam akım yoğunluğu sıfır olduğundan, yeni akım yoğunluğu aşağıdaki gibi olur [7].

$j=-\frac{1}{2} j \omega \sigma B_{z}\left(r-\frac{r_{0} t}{\ln (k) r} \frac{1}{r}\right)$

Burada k denklem (13)’te verilmiştir.

$k=\frac{r_{0}+t / 2}{r_{0}-t / 2}$

Önceki denkleme benzer şekilde, sarmaldaki kayıp, akım yoğunluğunun karesinin iletkenlik ile bölünen hacim integralidir. Bu integral şunları vermek için çözüldü:

$P_{a x}=\frac{1}{8} \omega^{2} \sigma B_{z}^{2} 2 \pi h\left[r_{0}^{3} t+\frac{r_{0} t^{3}}{4}-\frac{r_{0}^{2} t^{2}}{\ln (k)}\right]$

Ve birim hacim başına kayıp:

$P_{a x}=\frac{1}{8} \omega^{2} \sigma B_{z}^{2}\left[r_{0}+\frac{t^{2}}{4}-\frac{r_{0} t}{\ln (k)}\right]$

şeklinde olmaktadır.

Bu denklem, büyüklük olarak neredeyse eşit olan ancak zit işaretli iki terimin ve çok daha küçük bir büyüklüğe sahip bir terimin toplamını içerdiğinden, hesaplama sorununa neden olur. $\mathrm{Bu}, \mathrm{r}_{0}>>t$ tanımlanarak doğrulanabilir. Problemin üstesinden gelmek için logaritmik terim genişletilerek:

$\ln (k)=\ln \left(\frac{r_{0}+t / 2}{r_{0}-t / 2}\right)=\frac{t}{r_{0}}+\frac{t^{3}}{12 r_{0}^{3}}$

Bu değer yukarıdaki denkleme yerine yazılırsa, akının eksenel bileşeninden dolayı birim hacim başına sargı kaybı elde edilir: 
$P_{a x}=\frac{1}{32} \omega^{2} \sigma B_{z}^{2} t^{2}\left[\frac{16+t^{2} / r_{0}}{12+t^{2} / r_{0}}\right]$

Burada $\mathrm{P}_{\mathrm{ax}}$, akı yoğunluğunun eksenel bileşeninden kaynaklanan girdap kayıp, $\omega$ açısal frekans, $\sigma$ bakır iletkenliği, b iletken genişliği, $B_{z}$ akı yoğunluğunun eksenel bileşeni ve $r_{0}$ akı yoğunluğunun ortalama yarıçapıdır.

Burada, girdap akımı kayıplarının frekansın karesine ve akı yoğunluğuna bağlı olduğuna dikkat edilmelidir.

Ak1 yoğunluğu yük akımları tarafından verildiği için, aşırı harmonik akımlardan kaynaklanan kayıplar, temel harmonik kayıpları frekansın karesi ve yük kaybı ile orantılanarak doğru bir şekilde hesaplanabilir.

\section{TRANSFORMATÖRÜN ANSYS@MAXWELL İLE MODELLENMESİ}

Programda var olan olasılıkları göstermek için kurgusal bir transformatör modellenmiştir. Modellenen transformatörün özellikleri aşağıda Tablo 1'de verilmiştir. Sargıların ve çekirdeğin boyutları, bir tasarım programı kullanılarak hesaplanmış ve boyutları diğer benzer tipteki transformatörler için kolayca değiştirilebilecekleri parametreler kullanılarak ANSYS@Maxwell'e girilmiştir. Şekil 2'de modellenen transformatör sunulmuştur.

Tablo 1. Transformatörün özellikleri

\begin{tabular}{cc}
\hline YG & $33.000 \mathrm{~V}$ \\
\hline AG & $11.000 \mathrm{~V}$ \\
\hline Nüve Kaybı & $12.500 \mathrm{~W}$ \\
\hline Bakır Kaybı & $97.000 \mathrm{~W}$ \\
\hline Uk & $\% 11$ \\
\hline YG Bağlantı & DELTA \\
\hline AG Bağlantı & YILDIZ \\
\hline YG Spir Sayıs1 & 675 \\
\hline AG Spir Sayıs1 & 131 \\
\hline YG Faz Akımı & $152 \mathrm{~A}$ \\
\hline AG Faz Akımı & $785 \mathrm{~A}$ \\
\hline Io & $\% 0.44$
\end{tabular}

Bu model tasarlanan transformatörün gerçek değerleri ve gerçek boyutları ile program ortamında modellenmiştir. Bu yüzden bu model tüm transformatörü temsil etmektedir.

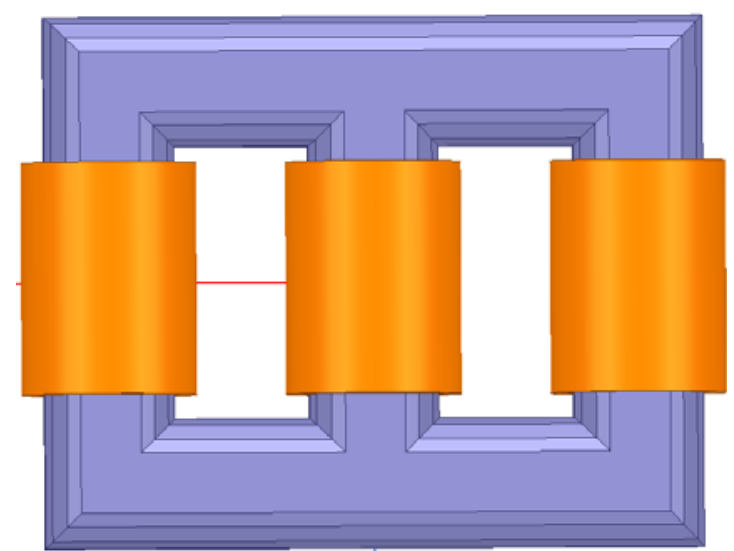

Şekil 2. Modellenen transformatör.

Program ortamında tasarlanan modelin çözümü ve analizi için modelin geometrisinde bir ağ sorunu çözmek için oluşturulur. Şekil 3’te modelin ağ örgüsü verilmiştir. 


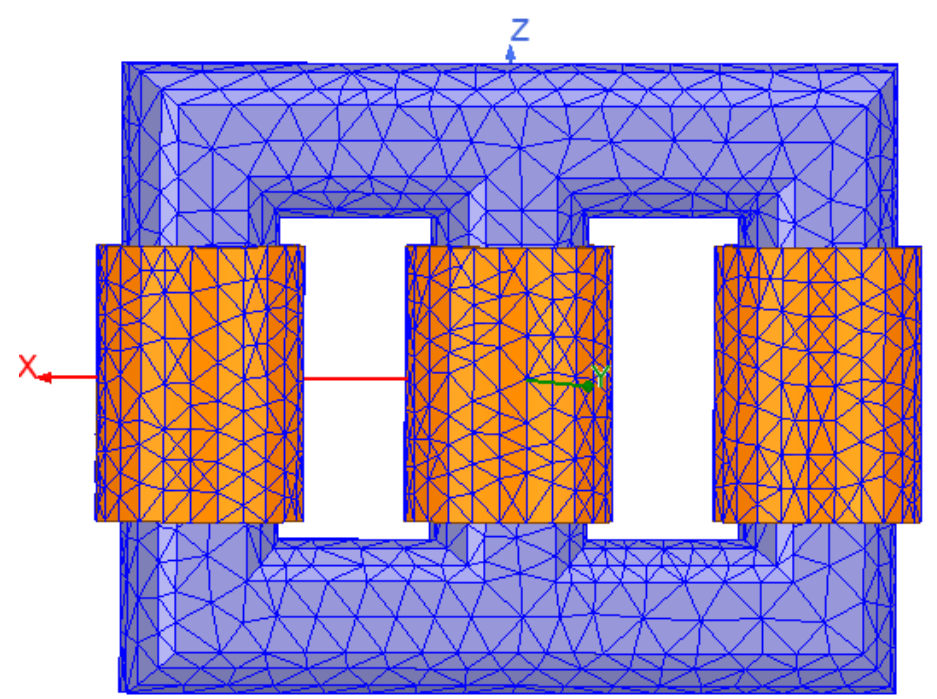

Şekil 3. Modellenen transformatörün ağ örgüsü.

Akı dağılımının elde edilmesi tüm bölgedeki alanın hesaplandığı anlamına gelir. Hesaplanan her düğümdeki vektör potansiyeli ve tüm değerler bu parametreden türetilebilir. Bu aşamada, her bir düğümün vektör potansiyelini koordinatlarıyla birlikte ANSYS @ Maxwell programı ile analiz etmek mümkündür. Şekil 4'te akı yoğunluğu dağ $11 ı m ı$ verilmiştir.

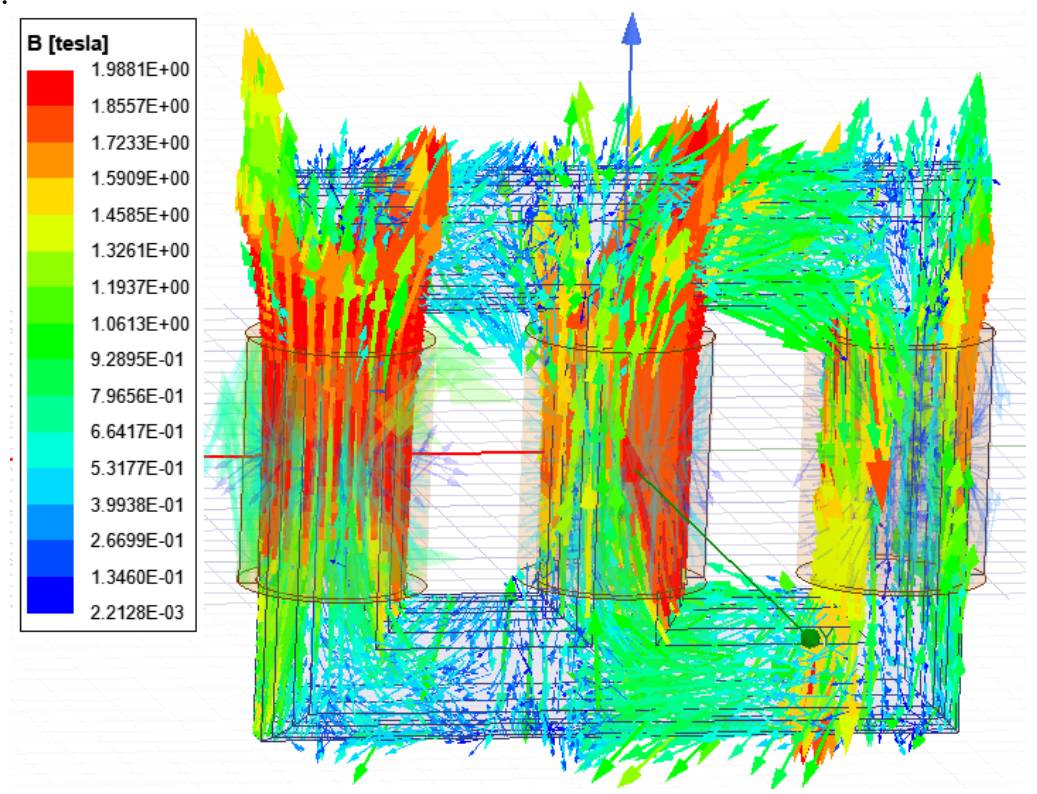

Şekil 4. Modellenen transformatörün manyetik akı dağılımının vektörel gösterimi.

Sonuçları ANSYS@Maxwell ile analiz etmek için, daha önce türetilen akı yoğunluğunun eksenel ve radyal bileşenlerinin kayıp formüllerini de programa tanıtmalıyı. Değerler, örneğin modeldeki sargı gibi her bir bölgeye entegre edilebilir. Bu özel modelin farklı bölgeleri vardır. Her bölge için yukarıda verilen formüller doğrudan bir yüzey integrali olarak da değerlendirilebilir. Modelin analizi hem normal koşullar altında hem de harmonik yük altında gerçekleştirilmiştir. Elde edilen sonuçlar karşılaştırılarak sunulmuştur. Tablo 2'de temel frekans için sargı kaybı hesaplamalarının sonuçları gösterilmektedir. 
Tablo 2. Temel frekans için sargı kaybı hesaplamalarının sonuçları

\begin{tabular}{c|cc}
\hline Değişkenler & Teorik Sonuçlar & $\begin{array}{c}\text { Simülasyon } \\
\text { Sonuçları }\end{array}$ \\
\hline $\begin{array}{c}\text { Girdap akım } \\
\text { Kaybı (kW) }\end{array}$ & 8.68 & 8.65 \\
\hline $\begin{array}{c}\text { Bakır Kaybı } \\
\text { (kW) }\end{array}$ & 97.600 & 103.1 \\
\hline $\begin{array}{c}\text { Manyetik Akı } \\
\text { (T) }\end{array}$ & 1.87 & 1.79 \\
\hline
\end{tabular}

Transformatörün sargılarındaki toplam kayıp tüm DC ve AC kayıplarının toplamıdır. Bu değerler sinüzoidal bir akım girişi için hesaplanır. Akım aşırı harmonik içeriğe sahipse, sargı kayıpları tam orantı ile hesaplanabilir. DC kayıpları, akımın karesiyle orantılıdır. Girdap kayıpları akım ve harmonik kare ile orantılıdır. Harmonik yük altındaki trafo kayıpları Tablo 3’te sunulmuştur.

Tablo 3. Harmonik yük altındaki kayıplar

\begin{tabular}{c|cc}
\hline Değişkenler & Teorik Sonuçlar & $\begin{array}{c}\text { Simülasyon } \\
\text { Sonuçları }\end{array}$ \\
\hline $\begin{array}{c}\text { Girdap akım } \\
\text { Kaybı (kW) }\end{array}$ & 9.69 & 11.6 \\
\hline $\begin{array}{c}\text { Bakır Kaybı } \\
(\mathbf{k W})\end{array}$ & 115.8 & 120.3 \\
\hline
\end{tabular}

Harmonik analizlerde görüldüğü üzere yük kayıpları artmıştır. Burada hem bakır kayıpları hem de nüve kayıpları artmaktadır. Nüve kayıplarının artmasının sebebi düzensiz manyetik akının nüve de dolaşmasıdır. Düzensiz akı dağılımının nüvedeki anlık dağılımı Şekil 6'da sunulmuştur. Yük kayıplarının transformatöre nasıl etki ettiğini görebilmek için ANSYS@Maxwell ve ANSYS@Workbench bütünleşik sistemi kullanılmıştır. Şekil 5’te tasarlanan modelin Maxwell ortamından Workbench ortamına aktarılması verilmiştir.

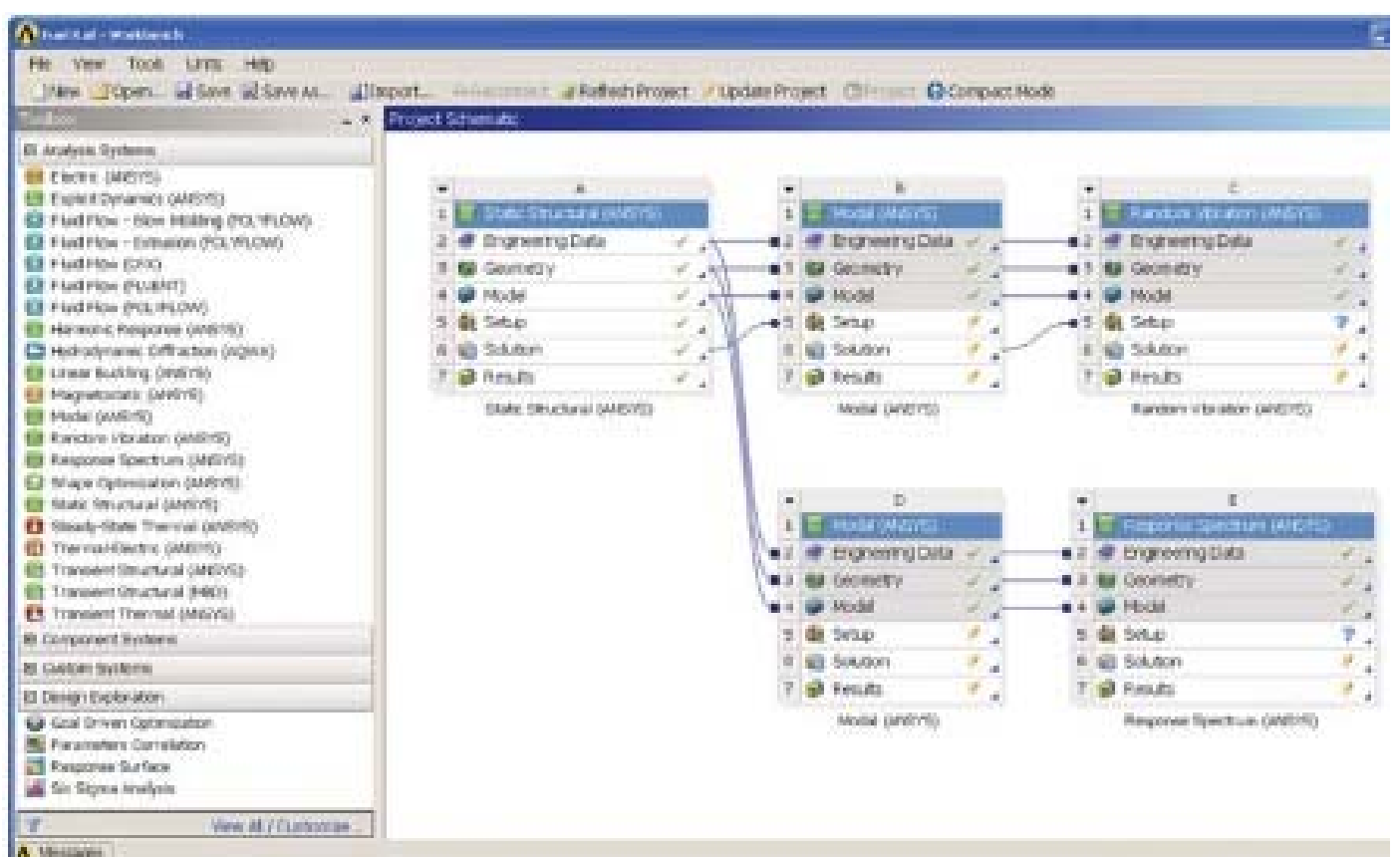

Şekil 5. Tasarlanan modelin Maxwell ortamından Workbench ortamına aktarılması 

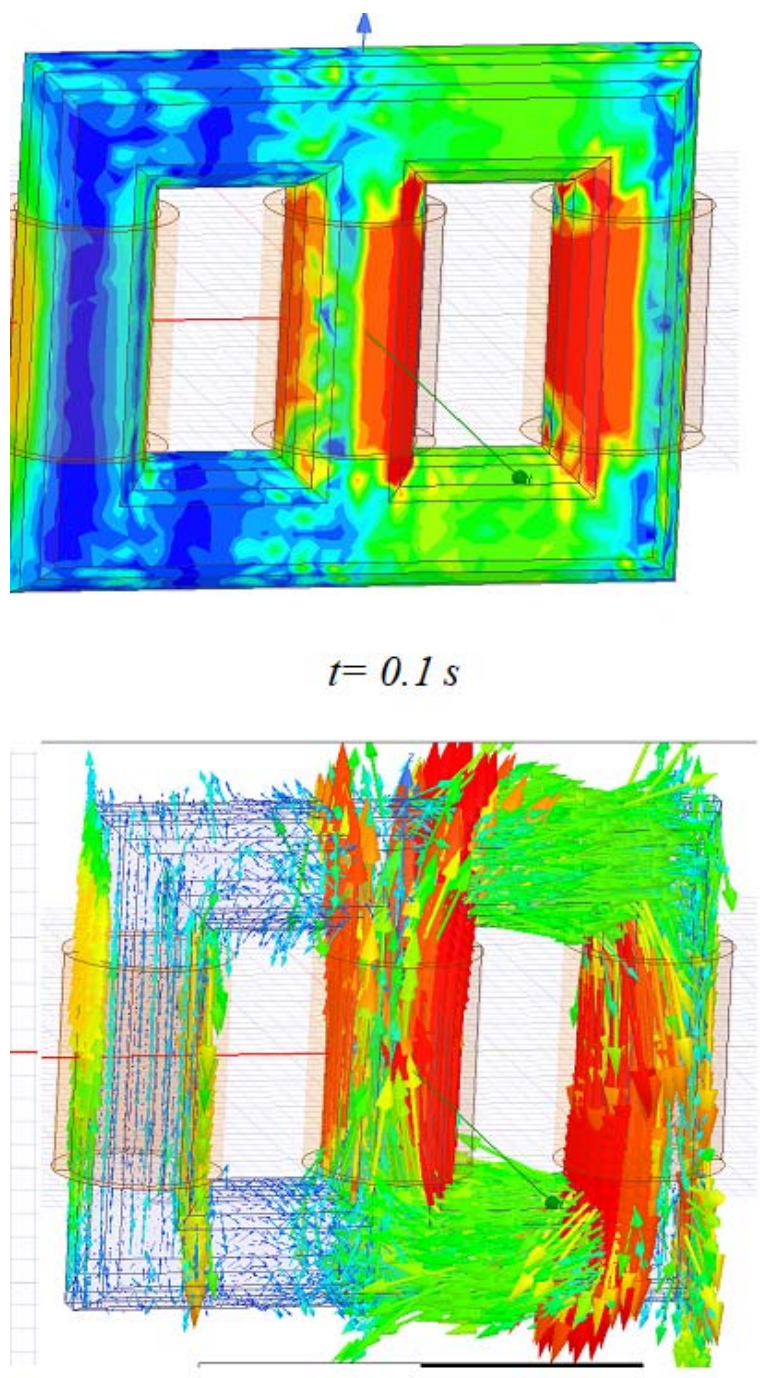

$$
t=0.0205 \mathrm{~s}
$$

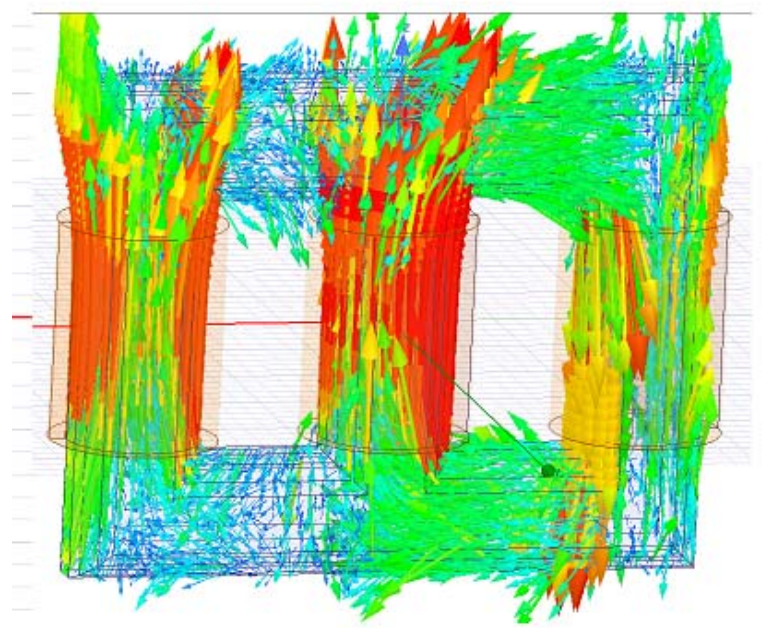

$$
t=0.0805 \mathrm{~s}
$$

Şekil 5. Nüvedeki düzensiz akı dağılımının ani olarak değişimi

Transformatörün sargılarında meydana gelen bakır kayıplarının artmasının sebebi, oluşan harmonik dalgalarının çalışma gerilimin tepe değerini sürekli değiştirmesidir. 


\section{SONUÇ}

Güç sistemlerindeki harmonik yükler, transformatörde ek kayılara ve 1sınmaya sebep olmaktadır. Bu durum trafonun beklenen kullanım ömrünün kısalmasına neden olur. Transformatör ömür kaybını doğru bir şekilde tahmin etmek için, harmonik akım spektrumunu, elektriksel özellikleri, termal davranışı, yükü ve ortam sıcaklığ profillerini hesaba katmak gerekir. Güç transformatörlerinde sargı kayıplarının hesaplanması için genel amaçlı sonlu eleman programlarının kolaylıkla kullanılabileceği gösterilmiştir. Güç sistemlerinde elektronik ekipmanın artan kullanımı, akımlarda harmonik bozulmalar yaratır. Bunlar, transformatörlerde aşırı kayıplara neden olabilir. $\mathrm{Bu}$ kayıpların dikkate alınması önemlidir, aksi takdirde sargıların aşııı ısınmasına ve limitlerin üzerindeki sıcak nokta sıcaklıklarına neden olabilirler. Bu sıcak noktalar transformatörün ömrünü kısaltabilir ve arızalara hatta trafonun patlamasına dahi neden olabilir. Bu çalışmada, gerçek bir transformatördeki harmonik akımların ürettiği aşırı sargı kayıpları analiz edilmiştir. İleride transformatörün sargılar dışında diğer kısımlarında meydana gelen başıboş kayıplar incelenebilir. Bu bölgelerde meydana gelen kayıplar, mevcut frekansın karesi ile orantılıdır. Ayrıca bu durum yağın bozulmasına neden olabilecek sıcak bölgeler oluşturabilir.

\section{Çıkar Çatışması}

Makale yazarı aralarında herhangi bir çıkar çatışması olmadığını beyan ederler

\section{KAYNAKÇA}

[1] Gupta, A. and R. Singh, COMPUTATION OF TRANSFORMER LOSSES UNDER THE EFFECTS OF NON-SINUSOIDAL CURRENTS. Advanced Computing: An International Journal, 2011.

[2] Susnjic, L., Z. Haznadar, and Z. Valkovic, 3D finite element determination of stray losses in power transformer. Electric Power Systems Research, 2008.

[3] Özüpak Y, MAMIS M. S, Realization of electromagnetic flux and thermal analyses of transformers by finite element method. IEEJ Transactions on Electrical and Electronic Engineering, 14(10), 1478-1484. Doi: 10.1002/tee.22966, 2019.

[4] K.T. Muthanna, A. Sarkar, K. Das, K. Waldner, "Transformer Insulation Life Assessment", IEEE Trans. Power Deliv. 21 (2006) 150 - 156.

[5] M. Lee, H. A. Abdullah, J. C. Jofriet, D. Patel, "Thermal modeling of disc-type winding for ventilated dry-type transformers", Electric Power Systems Research 80 121-129, 2010.

[6] Soh T. L. G, Said D. M, Ahmad N, Nor K. M, Salim F Experimental study on the impact of harmonics on transformer", IEEE 7th International Power Engineering and Optimization Conference (PEOCO), pp.686-690, 2013.

[7] K. Dursun, N. Rahmanov, Harmonic Load Losses in Power Transformer Windings Using Finite Element Methods, DOI: 10.1109/EUROCON.2013.6625180, july, 2013.

[8] D. Susa, M. Lehtonen, "Dynamic Thermal Modeling of Power Transformers:Further Development-Part I", IEEE Trans. Power Deliv. 21 (2006) 1961 - 1970.

[9] A. Elmoudi, M. Lehtonen, H. Nordman, "Effect of harmonic on transformers loss of life", in: Conference Record of IEEE International Symposium on Electrical Insulation, vol.2, 2006, pp.408-411.

[10] IEEE Std C57.100-1999, IEEE Standard Test "Procedure for Thermal Evaluation of Liquid-
Immersed Distribution and Power Transformers", 1999.

[11] S. Taheri, H. Taheri, I.Fofana, H. Hemmatjou, A. Gholami, "Effect of Power System Harmonics on Transformer Loading Capability and Hot Spot Temperature" 25th IEEE Canadian Conference on Electrical and Computer Engineering (CCECE), 2012.

[12] Özüpak Y, MAMIS M. S 2019 Realization of electromagnetic flux and thermal analyses of transformers by finite element method. IEEJ Transactions on Electrical and Electronic Engineering, 14(10), 1478-1484. Doi: $10.1002 /$ tee. 22966 .

[13] Özüpak Y, MAMIS M. S, TEKE İ. H 2019 Electromagnetic Field and Total Loss Analysis of Transformers by Finite Element Method. International Journal of Engineering And Computer Science, 8(1), 24451-24460. (Yayin No: 5774086)

[14] Yazdani-Asrami M, Mirzaie M, Akmal A. S 2013 No-load loss calculation of distribution transformers supplied by nonsinusoidal voltage using threedimensional finite element analysis, Energy, vol. 50, no. 1, pp. 205-219.

[15] Shareghi M, Phung B. T, Naderi M. S, Blackburn T. R, Ambikairajah E 2012 Effects of current and voltage harmonics on distribution transformer losses, International Conference on Condition Monitoring and Diagnosis (CMD), pp.633636 ,

[16] Soh T. L. G, Said D. M, Ahmad N, Nor K. M, Salim F 2013 Experimental study on the impact of harmonics on transformer", IEEE 7th International Power Engineering and Optimization Conference (PEOCO), pp.686-690.
ANSYS user guide 2020. 